\title{
Unanticipated Silyl Transfer in Enantioselective $\alpha, \beta-$ Unsaturated Acyl Ammonium Catalysis using Silyl Nitronates
}

\author{
Anastassia Matviitsuk, ${ }^{\dagger}$ Mark D. Greenhalgh, ${ }^{\dagger}$ James E. Taylor, ${ }^{\dagger}, \S$ Xuan B. Nguyen, ${ }^{\ddagger}$ David B. \\ Cordes, ${ }^{\dagger}$ Alexandra M. Z. Slawin, ${ }^{\dagger}$ David W. Lupton, ${ }^{*}{ }^{\ddagger}$ and Andrew D. Smith*,† \\ †EaStCHEM, School of Chemistry, University of St Andrews, North Haugh, St Andrews, Fife, KY16 9ST (UK) \\ ${ }^{\ddagger}$ School of Chemistry, Monash University, Clayton 3800, Victoria (Australia) \\ Supporting Information Placeholder
}

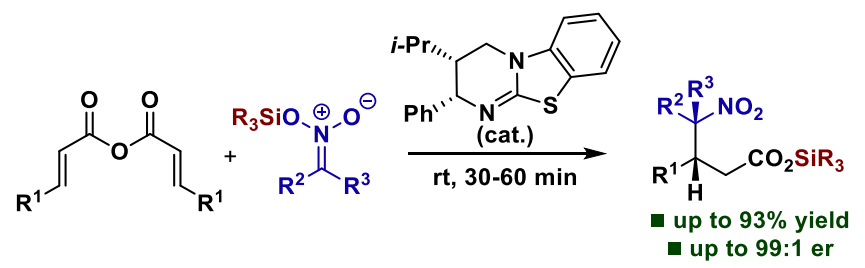

\begin{abstract}
The use of silyl nitronates is reported for the isothiourea-catalyzed synthesis of $\gamma$-nitro-substituted silyl esters containing up to two contiguous stereocenters in good yield and with excellent enantioselectivity (up to 93\% yield, 99:1 er). The serendipitously-discovered formation of silyl ester products in this reaction demonstrates a novel platform for catalyst turnover in $\alpha, \beta$-unsaturated acyl ammonium catalysis.
\end{abstract}

Within the field of Lewis base organocatalysis, the generation and exploitation of $\alpha, \beta$-unsaturated acyl ammonium intermediates has been showcased recently in a range of enantioselective catalytic processes. ${ }^{[1-3]}$ These synthetically versatile intermediates provide new avenues to access stereodefined products through electrophilic reactivity at the $C(1)$ and $C(3)$ positions, as well as latent nucleophilicity at $\mathrm{C}(2)$ (Scheme 1). Traditionally, such processes require a reaction partner that contains two nucleophilic sites to perform firstly $\mathrm{C}(3)$ conjugate addition and secondly intramolecular turnover of the Lewis base catalyst through addition at $C(1)$ (Scheme $1 a){ }^{[1-3]}$ To overcome this limitation, we recently reported the use of $\alpha, \beta$ unsaturated aryl esters as $\alpha, \beta$-unsaturated acyl ammonium precursors, where catalyst turnover was promoted by the aryloxide counterion released in situ during the reaction (Scheme 1b). ${ }^{[4]}$ While demonstrating successful proof-of-concept, this work was limited by the relatively long reaction times $(16 \mathrm{~h})$ and the requirement of using a nitroalkane as both the pronucleophile and the solvent. ${ }^{[5]}$ In this manuscript, a new protocol in $\alpha, \beta$-unsaturated acyl ammonium catalysis is demonstrated. Using silyl nitronates as reactants, ${ }^{[6]} \gamma$-nitro-substituted silyl ester products containing up to two contiguous stereocenters are obtained in good yield and with excellent enantioselectivity ( 12 examples, up to 95\% yield, 99:1 er) (Scheme 1c). The silyl nitronate is therefore not only required for the initial conjugate addition, but also serves an essential role in enabling catalyst turnover. Significantly, the cata- lytic reactions take $\leq 1 \mathrm{~h}$ and require only $1.5^{-2}$ equivalents of the silyl nitronate, allowing the application of structurally-diverse nitroalkane substrates in this methodology.

Scheme 1. Catalyst turnover strategies in $\alpha, \beta$ unsaturated acyl ammonium catalysis

$$
\text { a) Established reactivity using } \alpha, \beta \text {-unsaturated acyl ammoniums }
$$

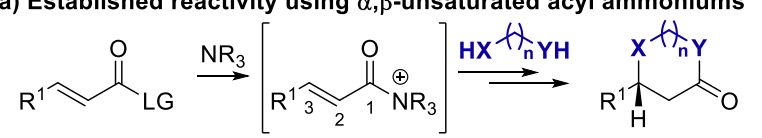

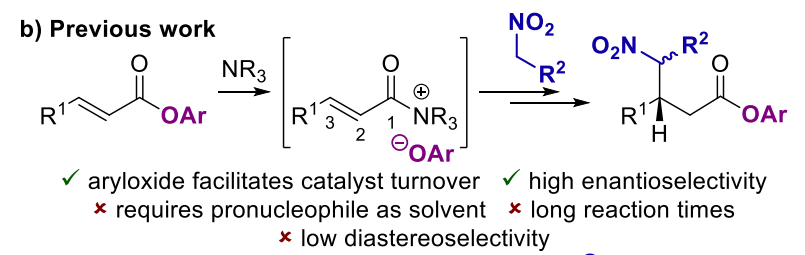

c) This work

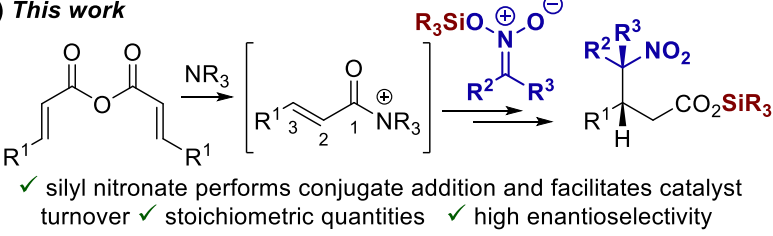

Initial studies investigated the application of silyl nitronates in an isothiourea-catalyzed Michael addition to $\alpha, \beta-$ unsaturated aryl ester $\mathbf{1}$ (Scheme 2a). Using silyl nitronate 2 (1 equiv), HyperBTM 3 as catalyst (20 mol \%), and $i$ $\mathrm{Pr}_{2} \mathrm{NEt}$ as base (1 equiv) in $\mathrm{MeCN}$ gave Michael addition 
product 4 in $45 \%$ yield and 95:5 er after $5 \mathrm{~h}$ at room temperature. Interestingly, a second Michael addition product was also observed $(\sim 5 \%)$, which was identified as silyl ester 5. Intrigued by the origin of this unanticipated product, further optimization studies focused on maximizing the yield of silyl ester $5^{[7]}$ Variation of the $\alpha, \beta$ unsaturated acyl ammonium precursor demonstrated that the use of $\alpha, \beta$-unsaturated anhydride 6 provided silyl ester 5 in $41 \%$ yield and an excellent 99:1 er (Scheme 2 b). Significantly, the reaction was complete within just 30 minutes. In addition to silyl ester $\mathbf{5}$, an approximately equal quantity of carboxylic acid $\mathbf{7}$ was identified in the crude reaction product mixture, ${ }^{[8]}$ indicating that $\sim 80 \%$ of the silyl nitronate had been transformed in the desired Michael addition process. Increasing the equivalents of silyl nitronate 2 (to 1.5 equiv) and using anhydrous MeCN[9] minimized the amount of carboxylic acid 7, allowing isolation of silyl ester 5 in 92\% yield and 99:1 er (Scheme 2c). This methodology therefore represents a significant advance over our previous work using $\alpha, \beta$ unsaturated aryl ester $\mathbf{1}$ and 2-nitropropane as solvent, in which only $46 \%$ of Michael addition product 4 was obtained after 16 h. ${ }^{[4]}$

\section{Scheme 2. Reaction optimization}

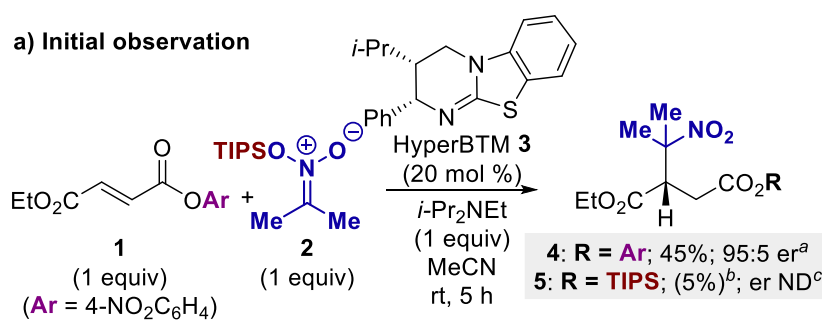

b) Use of anhydride substrate

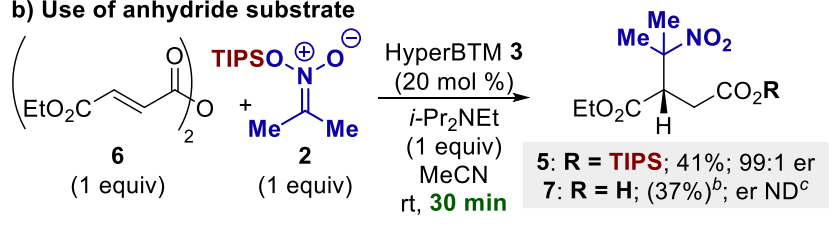

c) Optimized conditions

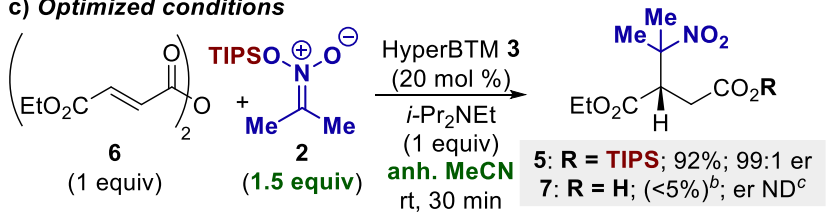

Isolated yields given; er determined by CSP-HPLC analysis; TIPS = triisopropylsilyl; ${ }^{a}$ er determined following conversion to the corresponding morpholinyl amide; ${ }^{[4]}{ }^{b}$ yield determined by ${ }^{1} \mathrm{H}$ NMR spectroscopy of the crude product mixture using an internal standard; ${ }^{c}$ $\mathrm{ND}=$ not determined.

Using 1.5 equiv of silyl nitronate, 1 equiv of $i-\mathrm{Pr}_{2} \mathrm{NEt}$ and $20 \mathrm{~mol} \%$ of HyperBTM 3 in anhydrous MeCN at room temperature for 30 minutes as standard, the scope and limitations of the method were investigated (Schemes 3 and 4). Variation of the $\beta$-substituent of the anhydride showed that methyl ester and morpholinyl amide substituents were tolerated, giving products 8 and 9 in excellent yield and with high enantioselectivity (Scheme 3). The absolute configuration of $\mathbf{9}$ was confirmed by single crystal X-ray analysis. The use of cinnamic anhydride did not provide the expected Michael addition product, but in- stead gave the isolable nitroso cinnamate ester derivative 10 in $55 \%$ yield. ${ }^{[10]}$ Based on literature precedent, this sideproduct 10 is proposed to form through $O$-acylation of the silyl nitronate followed by a formal [2,3]-sigmatropic rearrangement (Scheme 3, grey box). ${ }^{[1]}$ This result indicates that conjugate addition was disfavored in this case, and is consistent with previous examples of $\alpha, \beta$-unsaturated acyl ammonium catalysis where the presence of a $\beta$-electronwithdrawing group is often beneficial for activity.

Scheme 3. Reaction scope: Variation of $\alpha, \beta-$ unsaturated anhydride

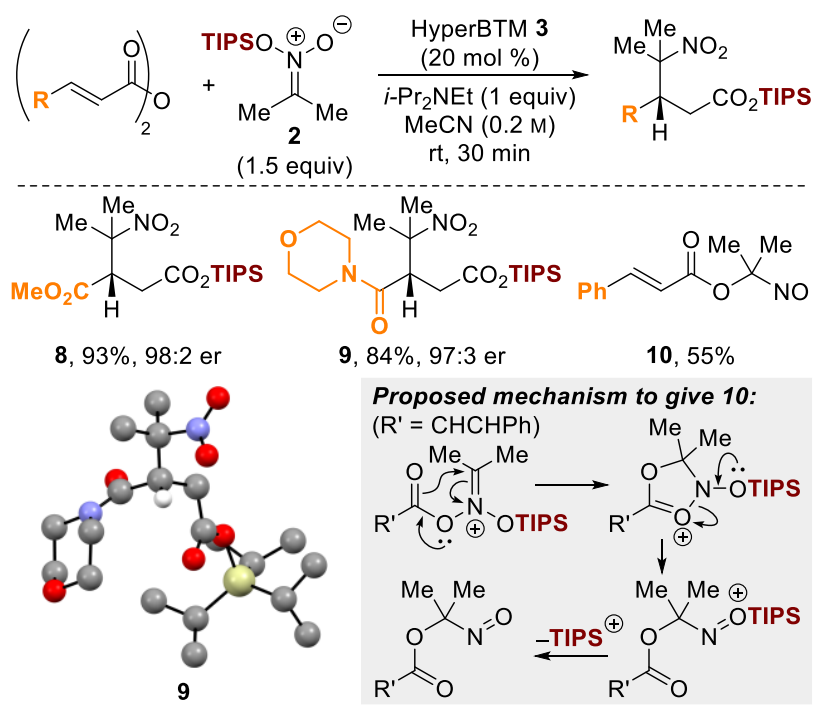

Isolated yields given; er determined by CSP-HPLC analysis; TIPS = triisopropylsilyl; majority of hydrogen atoms omitted for clarity from representation of X-ray crystal structure of $\mathbf{9}$.

The potential to apply this method to access more structurally-complex products was next probed through the use of a diverse set of silyl nitronate reactants (Scheme 4). The use of a cyclic silyl nitronate provided cyclohexylsubstituted derivative 11 in $60 \%$ yield and with excellent enantioselectivity (98:2 er), again in just 30 minutes. Notably, in our previous methodology, ${ }^{[4]}$ the use of nitrocyclohexane as the solvent provided no Michael addition product, emphasizing the vastly improved reactivity obtained by using silyl nitronates. The application of unsymmetrically-substituted silyl nitronates, leading to products containing two contiguous stereocenters, was investigated next. The use of a dialkyl-substituted nitronate allowed a single diastereoisomer of $\mathbf{1 2}$ to be isolated in $26 \%$ yield with >99:1 er. The relative and absolute configuration of 12 was confirmed by single crystal X-ray analysis following conversion to the benzylamide derivative 13. Signals corresponding to the other diastereoisomer could not be identified in the ${ }^{1} \mathrm{H}$ NMR spectra of the crude reaction mixture; however $\sim 50 \%$ of a nitroso fumarate ester product (analogous to 10) was also isolated, ${ }^{[7]}$ contributing to the low yield of $\mathbf{1 2}$. The nitroso ester product was presumably also formed following $O$ acylation of the silyl nitronate, and may be a consequence of the increased steric demands of this nitronate retarding the rate of the desired Michael addition. Next, a selec- 
tion of (hetero)aryl-alkyl-substituted nitronates was investigated. Michael addition products 14, 16 and 17 were obtained in moderate to good yield and with high enantioselectivity (94:6 to $96: 4$ er). The diastereoselectivity in each case was 70:30; however the diastereoisomers were readily separable by column chromatography. The relative and absolute configuration of the major diastereoisomer within this series was confirmed by single crystal $\mathrm{X}$-ray analysis following conversion of silyl ester $\mathbf{1 4}$ to the morpholinyl amide derivative $\mathbf{1 5}$. The protocol was further extended to monoaryl-substituted nitronates, ${ }^{[2,13]}$ with additional optimization showing that 2 equivalents of silyl nitronate and the absence of base was optimal for these substrates. ${ }^{[7]}$ Variation of the aryl group within this series provided Michael addition products 18-21 in good yield, $\sim 75: 25 \mathrm{dr}$ and consistently excellent er (up to $>99: 1$ ). The relative and absolute configuration of the major diastereoisomer within this series was confirmed by single crystal X-ray analysis following conversion of silyl ester 21 to the morpholinyl amide derivative 22.

Scheme 4. Reaction scope: Variation of silyl nitronate
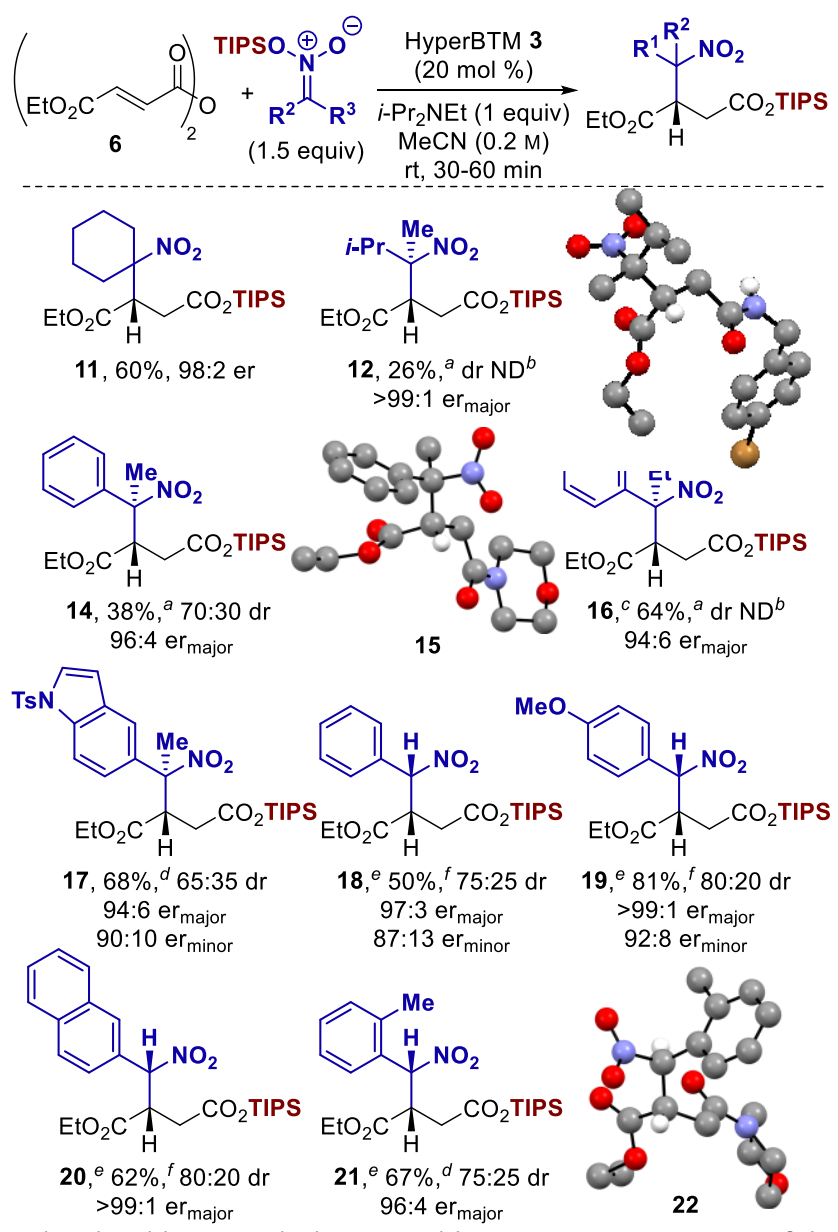

Isolated yields given; dr determined by ${ }^{1} \mathrm{H}$ NMR spectroscopy of the crude product mixture; er determined by CSP-HPLC analysis; TIPS = triisopropylsilyl; majority of hydrogen atoms omitted for clarity from representations of X-ray crystal structures of $\mathbf{1 3}, 15$ and 22. ${ }^{a}$ Product isolated as a single diastereoisomer; ${ }^{b} \mathrm{ND}=$ not determined; ${ }^{c}$ reaction performed at $\mathrm{o}{ }^{\circ} \mathrm{C} ;{ }^{d}$ each diastereoisomer isolated separately, yield given is the sum of both diastereoisomers; ${ }^{e} 2$ equiv silyl nitronate and no $i$ - $\mathrm{Pr}_{2} \mathrm{NEt}$ used; ${ }^{f}$ isolated yield is of a mixture of diastereoisomers.
Epimerization studies were performed to provide insight into the origin of diastereoselectivity for each series of silyl nitronate (Scheme 5). Applying a single diastereoisomer of $\mathbf{1 4}$ under the standard reaction conditions resulted in no change in diastereo- or enantiopurity (Scheme 5a), indicating that the $\sim 70: 30 \mathrm{dr}$ obtained in the catalytic reaction arises from kinetic control. In contrast, when a single diastereoisomer of $\mathbf{2 1}$ was treated with HyperBTM ( $20 \mathrm{~mol} \%)$ in $\mathrm{MeCN}$, the $\mathrm{dr}$ readjusted to $78: 22$ within 30 minutes (Scheme $5 \mathrm{~b}$ ). This result can be rationalized by epimerization at the $C\left(1^{\prime}\right)$ stereocenter ( $\alpha$ to the $\mathrm{NO}_{2}$ group), indicating that the diastereoselectivity observed in the catalytic reaction most likely reflects the relative thermodynamic stability of the two diastereoisomers.

\section{Scheme 5. Epimerization studies}
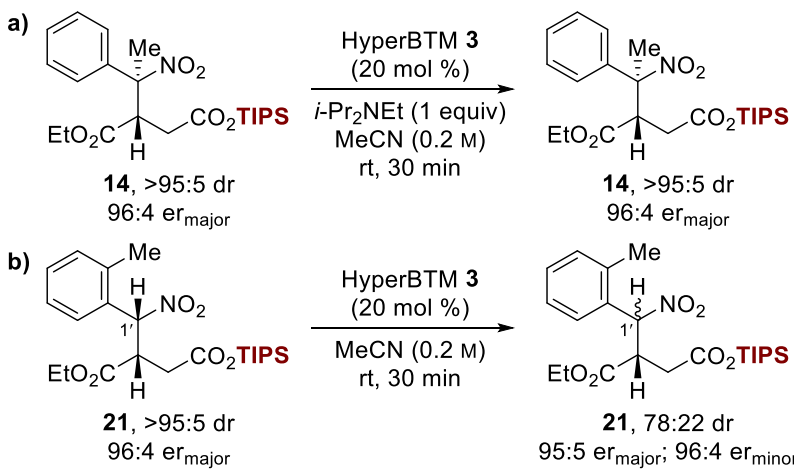

$96: 4$ er

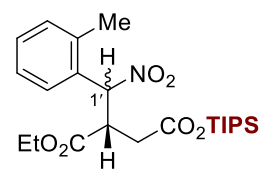

21, 78:22 dr 95:5 er major $; 96: 4$ er $_{\text {minor }}$

$\mathrm{dr}$ determined by 'H NMR spectroscopy of the crude product mixture; er determined by CSP-HPLC analysis; TIPS = triisopropylsilyl.

Based on previous work, ${ }^{[1-4]}$ the following reaction mechanism is tentatively outlined (Scheme 6a). $N$-Acylation of HyperBTM 3 by $\alpha, \beta$-unsaturated anhydride 23 gives the key $\alpha, \beta$-unsaturated acyl isothiouronium intermediate $\mathbf{2 4}$, to which the silyl nitronate $\mathbf{2 5}$ undergoes stereoselective Michael addition. The $\alpha, \beta$-unsaturated acyl isothiouronium 24 is believed to adopt an s-cis conformation, with a syn-coplanar non-covalent $1,5-\mathrm{O} \cdot \cdots \mathrm{S}$ interaction providing a conformational lock. ${ }^{[2 c, 3 a, 14,15]}$ The stereochemical outcome of the reaction can be rationalized by the stereodirecting phenyl substituent of the isothiourea catalyst controlling Michael addition of the silyl nitronate to the $\mathrm{Si}$-face of $\alpha, \beta$-unsaturated acyl isothiouronium 24 to give ammonium enolate $26 .{ }^{[16]}$ To release silyl ester product $\mathbf{2 7}$ and regenerate HyperBTM 3, three events are required: (i) protonation at $\mathrm{C}(2)$, (ii) incorporation of an oxygen atom, and (iii) silyl transfer. A variety of reasonable mechanisms can be postulated in which these steps can take place in any order. One of the simplest possibilities is desilylation of alkyl nitronium ion $\mathbf{2 6}$ by adventitious water to generate silanol 29, which is then responsible for catalyst turnover; however, control experiments suggest that direct $O$ acylation of silanol 29 is unlikely (Scheme 6b). Although alternative mechanisms for catalyst turnover can be spec- 
ulated, ${ }^{[7]}$ differentiation between these possibilities is the subject of on-going investigations and is beyond the scope of this communication.

Scheme 6. Mechanistic outline and control studies

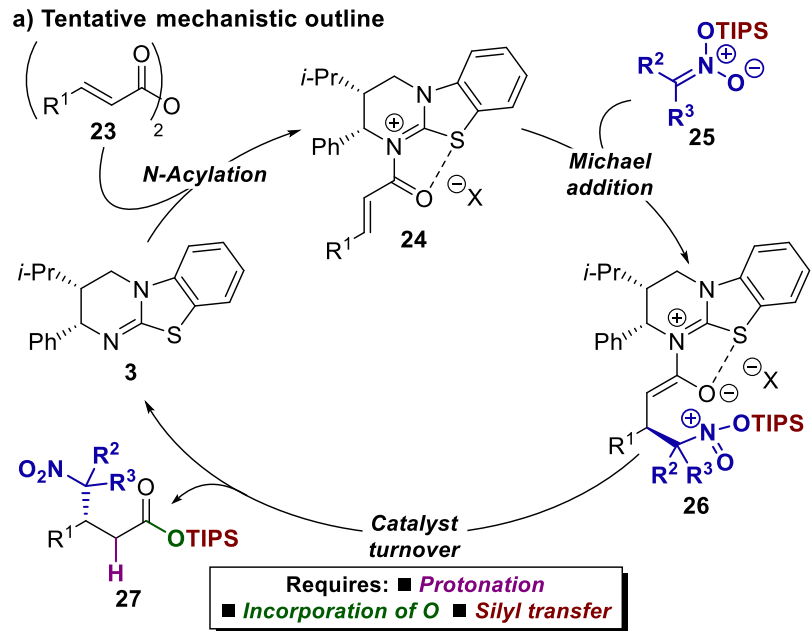

b) Feasibility of silanol involvement in catalyst turnover ${ }^{a}$

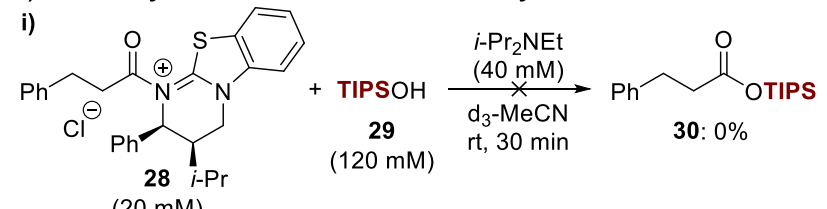

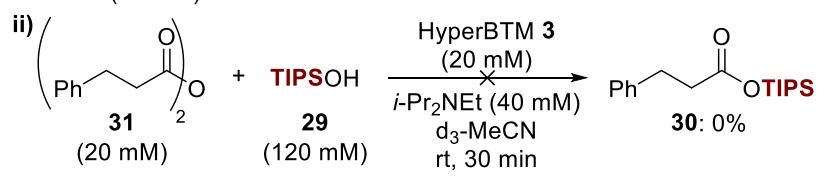

${ }^{a}$ Followed by in situ ${ }^{1} \mathrm{H}$ NMR spectroscopy through comparison to authentic samples of expected reaction products.

In conclusion, a new approach for isothiourea catalyst turnover in $\alpha, \beta$-unsaturated acyl ammonium catalysis has been demonstrated. The use of a silyl nitronate in this Michael addition was essential to promote catalyst turnover, giving $\gamma$-nitro-substituted silyl esters with up to two contiguous stereocenters in good yield and with excellent enantioselectivity (12 examples, up to 93\% yield, >99:1 er). The catalytic reactions are complete within $1 \mathrm{~h}$, and require only $1.5^{-2}$ equivalents of the silyl nitronate. This methodological advance therefore allows significantly more valuable, bespoke and structurally-diverse nitroalkane substrates to be applied in $\alpha, \beta$-unsaturated acyl ammonium conjugate additions for the first time. Further investigation and exploitation of the synthetic potential and mechanistic aspects of this catalyst turnover approach is currently underway in our laboratory. ${ }^{[17]}$

\section{ASSOCIATED CONTENT}

\section{Supporting Information}

The Supporting Information is available free of charge on the ACS Publications website.

Experimental details, compound characterization, NMR spectra, HPLC traces (PDF).

\section{Accession Codes}

CCDC 1962792-1962795 contain the supplementary crystallographic data for this paper. These data can be obtained free of charge via www.ccdc.cam.ac.uk/data_request/cif, or by emailing data_request@ccdc.cam.ac.uk, or by contacting The Cambridge Crystallographic Data Centre, 12 Union Road, Cambridge CB2 1EZ, UK; fax: +44 1223336033.

\section{AUTHOR INFORMATION}

\section{Corresponding Author}

*E-mail: adsio@st-andrews.ac.uk

*E-mail: David.Lupton@monash.edu

\section{Present Addresses}

$\S$ James E. Taylor, Department of Chemistry, University of Bath, Claverton Down, Bath, BA2 7AY, (UK).

\section{Notes}

The authors declare no competing financial interest.

\section{ACKNOWLEDGMENT}

We thank the European Research Council under the European Union's Seventh Framework Programme (FP7/2007-2013) ERC grant agreement no. 279850 (A.D.S.), the EPSRC (EP/Jo18139/1, A.M.) and the Royal Society of Chemistry (Researcher Mobility Grant). A.D.S. thanks the Royal Society for a Wolfson Research Merit Award. D.W. L. thanks the Australian Research Council for a discovery Award (DP170103567). We also thank the EPSRC UK National Mass Spectrometry Facility at Swansea University.

\section{REFERENCES}

1. For a review see: Vellalath, S.; Romo, D. Angew. Chem. Int. Ed. 2016, 55, 13934-13943.

2. For seminal examples see: (a) Bappert, E.; Müller, P.; Fu, G. C. Chem. Commun. 20o6, 2604-26o6. (b) Pandiancherri, S.; Ryan, S. J.; Lupton, D. W. Org. Biomol. Chem. 2012, 10, 7903-7911. (c) Robinson, E. R. T.; Fallan, C.; Simal, C.; Slawin, A. M. Z.; Smith, A. D. Chem. Sci. 2013, 4, 2193-2200. (d) Vellalath, S.; Van, K. N.; Romo, D. Angew. Chem. Int. Ed. 2013, 52, 13688-13693. (e) Liu, G.; Shirley, M. E.; Van, K. N.; McFarlin, R. L.; Romo, D. Nat. Chem. 2013, 5, 1049-1057. 
3. For selected recent examples see: (a) Abbasov, M. E.; Hudson, B. M.; Tantillo, D. J.; Romo, D. Chem. Sci. 2017, 8, 1511-1524. (b) Fukata, Y.; Yao, K.; Miyaji, R.; Asano K.; Matsubara, S. J. Org. Chem. 2017, 82, 12655-12668. (c) Kang, G.; Yamagami, M.; Vellalath, S.; Romo, D. Angew. Chem. Int. Ed. 2018, 57, 6527-6531. (d) Greenhalgh, M. D.; Qu, S.; Slawin, A. M. Z.; Smith, A. D. Chem. Sci. 2018, 9, 4909-4918.

4. Matviitsuk, A.; Greenhalgh, M. D.; Barrios Antúnez, D.-J.; Slawin, A. M. Z.; Smith, A. D. Angew. Chem. Int. Ed. 2017, 56, 12282-12287.

5. We have recently expanded the scope of aryloxidefacilitated catalyst turnover to include the use of $\mathrm{N}$-heterocyclic pronucleophiles, see: Shu, C.; Liu, H.; Slawin, A. M. Z.; Carpenter-Warren, C.; Smith, A. D. Chem. Sci. 2019, DOI: 10.1039/c9sco4303a.

6. For examples of silyl nitronates being used in enantioselective catalysis see: (a) Knudsen, K. R.; Risgaard, T.; Nishiwaki, N.; Gothelf, K. V.; Jørgensen, K. A. J. Am. Chem. Soc. 2001, 123, 58435844. (b) Risgaard, T.; Gothelf, K. V.; Jørgensen, K. A. Org. Biomol. Chem. 2003, 1, 153-156. (c) Ooi, T.; Doda, K.; Maruoka, K. J. Am. Chem. Soc. 2003, 125, 2054-2055. (d) Ooi, T.; Doda, K.; Maruoka, K. J. Am. Chem. Soc. 2003, 125, 9022-9023. (e) Ooi, T.; Doda, K.; Takada, S.; Maruoka, K. Tetrahedron Lett. 2oo6, 47, 145-148. (f) Wilson, J. E.; Casarez, A. D.; MacMillan, D. W. C. J. Am. Chem. Soc. 2009, 131, 11332-11334.

7. See the Supporting Information for further details.

8. The er of carboxylic acid side-product 7 was not assessed.

9. Anhydrous $\mathrm{MeCN}$ was obtained following distillation over $\mathrm{CaH}_{2}$. The use of anhydrous MeCN purchased from Acros Organics provided comparable results.

10. Nitroso acetates are most commonly synthesized by the oxidation of oximes, see: (a) Lown, J. W. J. Chem. Soc. B 1966, 441-446. (b) Kropf, V. H.; Lambeck, R. Justus Liebigs Ann. Chem. 1966, 700, 1-17. (c) Shafiullah, D.; Ali, H. Synthesis 1979, 124-126. (d) Moriarty, R. M.; Prakash, O.; Vavilikolanu, P. R. Synth. Commun. 1986, 16, 1247-1254. (e) Calvet, G.; Dussaussois, M.; Blanchard, N.; Kouklovsky, C. Org. Lett. 2004, 6, 2449-2451. (f) Sha, X.; Isbell, T. S.; Patel, R. P.; Day, C. S.; King, S. B. J. Am. Chem. Soc. 2006, 128, 9687-9692.

11. (a) White, H. E.; Considine, J. W. J. Am. Chem. Soc. 1958, 8o, 626-63o. (b) Daineko, V. I.; Proskurnina, M. V.; Skornyakov, Y. V.; Trofimov, B. A.; Zefirov, N. S. Russ. J. Org. Chem. 2002, 38, 1431-1433. (c) Kokuev, A. O.; Anatonova, Y. A.; Dorokhov, V. S.; Golovanov, I. S.; Nelyubina, Y. V.; Tabolin, A. A.; Sukhorukov, A. Y.; Ioffe, S. L. J. Org. Chem. 2018, 83, 11057-11066.

12. Monoalkyl-substituted nitronates are also applicable as substrates. For example, reaction of $\alpha, \beta$-unsaturated anhydride 6 with the silyl nitronate derived from 1-nitropropane provided the corresponding $\gamma$-nitro silyl ester in 68\%, 55:45 dr and with excellent enantioselectivity (97:3 $\mathrm{er}_{\text {major }}$; $96: 4 \mathrm{er}_{\text {minor }}$ ) - see supporting information pages $\mathrm{S}_{2} 6-27$ for full details.

13. Silyl nitronates derived from nitromethane have been stated as being potentially explosive and therefore their use was not investigated in this work (see ref. 6f).

14. (a) Liu, P.; Yang, X.; Birman, V. B.; Houk, K. N. Org. Lett. 2012, 14, 3288-3291. (b) Abbasov, M. E.; Hudson, B. M.; Tantillo, D. J.; Romo, D. J. Am. Chem. Soc. 2014, 136, 4492-4495. (c) Robinson, E. R. T.; Walden, D. M.; Fallan, C.; Greenhalgh, M. D.; Cheong, P. H.-Y.; Smith, A. D. Chem. Sci. 2o16, 7, 6919-6927. (d) West, T. H.; Walden, D. M.; Taylor, J. E.; Brueckner, A. C.; Johnston, R. C.; Cheong, P. H.-Y.; Lloyd-Jones, G. C.; Smith, A. D. J. Am. Chem. Soc. 2017, 139, 4366-4375. (e) Greenhalgh, M. D.; Smith, S. M.; Walden, D. M.; Taylor, J. E.; Brice, Z.; Robinson, E. R. T.; Fallan, C.; Cordes, D. B.; Slawin, A. M. Z.; Richardson, H. C.; Grove, M. A.; Cheong, P. H.-Y.; Smith, A. D. Angew. Chem. Int. Ed. 2018, 57, 3200-3206.

15. Pascoe, D. J.; Ling, K. B.; Cockroft, S. L. J. Am. Chem. Soc. 2017, 139, 15160-15167.
16. Desilylation of the silyl nitronate may take place prior to, or during, Michael addition, however alkyl nitronium ion 26 is shown to avoid implied knowledge of the stage at which desilylation takes place. See supporting information for more discussion.

17. Research data underpinning this publication can be found at: $\quad$ https://doi.org/10.1763o/987798e4-e872-4007-bc92$931 c 73232 a 6 b$ 